\title{
Kamu Hizmetlerinin Sunumunda Dijital Dönüşüm: Nesnelerin İnterneti Üzerine Bir İnceleme
}

\author{
Volkan GÖÇOĞLU ${ }^{1}$
}

Öz

Son yıllarda bilgi ve iletişim teknolojilerinde yaşanan gelişmeler, internet kullanımının yaygınlaşması, bilgi çağına ve bilgi toplumu olarak nitelendirilen döneme geçiş ile birlikte kamu hizmetlerinin sunum şekli de dönüşüme uğramıştır. Birbirlerine internet aracıllğıyla bağlı hale gelen insanlar, makineler, taşıtlar, eşyalar, kısaca nesneler, nesnelerin interneti adı verilen konuyu kamu yönetimi gündemine taşımışır. Nesnelerin internetinin bir yansıması olarak merkezi ve yerel yönetimler, kamu hizmetlerini daha etkin, etkili ve verimli sunmak adına sensörler, gelişmiş ağlar, giyilebilir teknolojiler ve GPS sistemlerini kamu hizmetlerinde kullanmaya başlamışlardır. Bu uygulamalar kamu hizmetleri sunumunda yaşanan dijital dönüşümün somut birer örneklerini teşkil etmektedirler. Bu çalışma, kamu hizmeti sunumunda gözlemlenen dijital dönüşümü kamu yönetimi disiplini temelinde, nesnelerin interneti konusu bağlamında, ilgili alan yazını ve raporlar çerçevesinde analiz etmektedir. Çalışmada, nesnelerin interneti kapsamına giren uygulamalar, çeşitli kamu hizmetleri alanları dâhilinde ele alınmakta ve uygulamaya yönelik örnekler verilmektedir. Çalışmanın sonuç bölümünde ise konu üzerine gelecekte yapılacak olan çalışmalar için bir takım öneriler sunulmaktadır.

Anabtar Kelimeler: Kamu Hizmeti Sunumu, Nesnelerin İnterneti, Dijital Dönüşüm, E-Devlet

\section{Digital Transformation in Delivery of Public Services: An Investigation on Internet of} Things

\begin{abstract}
In recent years, the development of information and communication technologies, the widespread use of the internet, the transition to the information age and the so-called information society, as well as the form of public services has been transformed. People, machines, vehicles, goods, objects in short, which became connected to each other via internet, brought the subject called internet of objects to the public administration agenda. As a reflection of the Internet of objects, central and local governments have begun to use sensors, advanced networks, wearable technologies and GPS systems in public services more effectively, effectively and efficiently. These practices are concrete examples of the digital transformation in the provision of public services. This study analyzes the digital transformation observed in the provision of public services on the basis of public administration discipline, in the context of the Internet of Things, within the relevant literature and reports. In this study, the applications within the scope of the internet of objects are handled within various public services areas and examples are given. In the conclusion part of the study, some suggestions are given for future studies on the subject.
\end{abstract}

Key Words: Public Services Delivery, Internet of Things, Digital Transformation, E-Government

\section{Atıfta İçin / Please Cite As:}

Göçoğlu, V. (2020). Kamu hizmetlerinin sunumunda dijital dönüşüm: nesnelerin interneti üzerine bir inceleme. Manas Sosyal Arastirmalar Dergisi, 9(1), 615-628.

\footnotetext{
${ }^{1}$ Dr. Öğr. Üyesi - Afyon Kocatepe Üniversitesi Dinar Uygulamalı Bilimler Yüksekokulu, volkangocoglu@gmail.com ORCID: 0000-0002-7036-2416
} 


\section{Giriş}

Kamu hizmeti anlayışı ve sunumu kültür, ideolojiler, devletlerin yönetim biçimleri, ekonomik ve siyasi ortam gibi çeşitli unsurların etkisiyle gelişim gösterebilmektedir. Bu unsurlar, sahip olduklan iç ve dış dinamiklere göre ülkeden ülkeye farklılıklar gösterebilmektedir. Bunun yanında ülkelerin kamu hizmeti anlayışını ve sunumunu etkileyen, küresel çapta gelişmeler de olabilmektedir. Devletlerinin sınırlarını belirsiz hale getiren küreselleşme süreci, bilginin kullanım ve paylaşım şekillerinin değiştiği bilgi toplumu ve bilgi çağı, bunların bir yansıması olarak ortaya çıkan Web 2.0, Endüstri 4.0 gibi akım ve anlayışlar söz konusu küresel çaptaki gelişmelere örnek olarak gösterilebilir.

İçinde bulunulan dönem olan bilgi çağında teknolojinin gelişimi, ülkelerde internet kullanımının hızla yayılması, gelişen teknolojiye bağlı olarak işlerin daha kolay yapılabilmesi adına geliştirilen "öğrenen makineler" ve "akıllı cihazlar" hizmet sunumunda kullanılmak üzere öncelikle özel sektör daha sonra da kamu sektörünün ilgisini çekmiştir. Hizmetlerin daha etkin, etkili ve verimli sunumu için hem merkezi hem de yerel kamu yöneticileri ve kamu kurumları özellikle E-Devlet uygulamaları ile vatandaşlara dijitalleşmiş kamu hizmetleri vermeye başlamışlardır (Castro vd., 2016; Gül, 2018; Schou ve Hjelhot, 2018). Böylece kamu hizmetlerinin sunumunda bir dijital dönüşüm dönemi başlamıss, E-Devlet, akıllı şehirler, nesnelerin interneti, büyük veri gibi kavramlar kamu yönetimi alan yazınında bir hayli kullanılır hale gelmiş, bunun ötesinde de bu kavramları konu alan akademik çalışmalar yapılmaya başlamışıtır. Bu çalışma, kamu yönetiminde hizmet sunumunun dijital dönüşümü konusunu henüz Türkçe alan yazınında genel hatları tam olarak oluşturulmamış olan "nesnelerin interneti" kavramı etrafinda analiz etmektedir. Çalısma, "Kamu hizmetlerinin sunumunda dijital dönüşümün boyutları nelerdir ve yeni kamu hizmetleri sunumunda nesnelerin internetinin yeri neresidir?” araştırma sorusuna cevap aramaktadır. Bu doğrultuda, araştırma sorusuna cevap bulabilmek adına geniş Türkçe ve özellikle (konuda daha gelişmiş olan) İngilizce kamu yönetimi alan yazınında geniş bir tarama yapılmışırı. Akademik çalışmalara ek olarak daha çok özel şirketlerce oluşturulmuş olan, konu ile ilgili raporlar da irdelenmiştir. Neticede, çalışmanın ilk bölümünde kamu hizmeti ve sunumunun kavramsal çerçevesi çizilmiş, akabinde kamu hizmeti sunumunda dijital dönüşüm konusu tüm boyutlarıyla ele alınmıştır. Çalışmanın son bölümünde ise nesnelerin interneti konusu genel kamu hizmeti alanları içerisinde örneklerle ele alınarak bu oluşumun kamu hizmeti sunumundaki yeri belirlenmeye çalışılmıştır. Araştırmanın sonuç bölümünde ise yapılan tarama sonucunda gözlemlenen eksik alanlar ve konu ile ilgili gelecekte yapılacak çalışmalara yönelik birtakım öneriler sunulmuştur.

\section{Kamu Hizmeti ve Sunumu}

Kamu kavramı, genellikle bir ülke içerisinde yaşayan insanların tümü olarak nitelendirilmekte ve "Özel” kelimesinin karşıt anlamlısı olarak kullanılmaktadır. Kelimenin Arapçası olan "amme” sözcügü de nadiren de olsa halen kamu kelimesinin eş anlamlısı olarak kullanılmaktadır. Türk Dil Kurumunun (TDK) Büyük Türkçe Sözlügünde ise kelime "halk hizmeti gören devlet organlarının tümü" şeklinde tanımlanmaktadır (TDK, 2019). Söz konusu tanıma benzer şekilde Romalılarda, "res publica” olarak isimlendirilen ve "kamusal şey" olarak Türkçeye çevrilebilecek olan kavram, kamu hizmetlerinin sunumu için ihtiyaç duyulan binalar, mekanizmalar ve diğer tüm fiziki etmenleri tanımlamak üzere kullanılmaktadır. Yıldız (2011, s. 1) kamu kavramını ise en geniş anlamıla insan faaliyetlerinin; toplumun ve devletin müdahalesi veya düzenlemesi gereken kısmı olarak tanımlanmaktadır (Göçoğlu, 2014, s. 7).

Kamu hizmeti kavramı ise kamu kavramı gibi belirli ve genel geçer bir tanıma sahip değildir (Çal, 2009, s. 6; Şen ve Acar, 2017, s. 148; Sezer ve Vural, 2010, s. 205; Çapar vd., 2015, s. 363). Bunun nedeni kavramın ve kavramın zeminlerini oluşturduğu anlayışın zamana, ideolojilere ve mekana göre değişiklik gösterebilecek bir kavram olmasıdır (Eser vd., 2011, s. 210). Kavramın tanımsal sınırları daha çok idare hukuku sınırları içerisinde ve idare hukukçuları tarafından çizilmeye çabalanmıștır. Türkiye'de, Türk İdare Hukuku alanında en önemli isim olarak kabul edilen Onar (1992, s. 13), kamu hizmetini "devlet veya diğer kamu tüzel kişileri tarafından veya bunların gözetim ve denetimi altında genel, kolektif ihtiyaçları karşılamak, kamu yararını sağlamak için kamuya sunulmuş olan devamlı ve muntazam faaliyetler" şeklinde tanımlamıştır. Gözler (2003, s. 219) ise kavramı, "bir kamu tüzel kişisi veya onun denetimi altında bir özel kişi tarafından yürütülen kamu yararı amacına yönelik faaliyetler" şeklinde tanımlamıştır. Alan yazınında en çok kabul gören bu iki tanım doğrultusunda kamu hizmeti kavramının temel iki unsur etrafinda şekillendiği söylenebilecektir (Şen ve Acar, 2017, s. 148). Bir hizmetin kamu hizmeti olarak nitelendirilebilmesi için öncelikle söz konusu hizmetin kamuya yönelik olması ve kamu yararını hedeflemesi gerekmektedir. Diğer yandan bu hizmetin bizzat ilgili kamu kuruluşlarınca veya kamu kuruluşlarının denetimi ve gözetiminde 
olan özel kişi ya da kuruluşlarca yürütülmesi gerekmektedir. Bu iki unsur temelinde kamu hizmeti, idarenin yapmakla yükümlü olduğu bir hizmet olarak görülebilecektir (Giritli ve Akgüner, 1987, s. 27 Akt: Sezer, 2008 , s. 149). Bu yönleriyle kamu hizmeti bir faaliyeti belirtmekte ise de, kavram aynı zamanda kamu kurum ve kuruluşlarının kendilerini niteler şekilde de kullanılmaktadır. Örneğin, 1982 Anayasası'nın 128. maddesinde kamu hizmeti, hizmet sunumu filini belirtirken, Anayasa'nın 70. maddesinde ise kamu kurum ve kuruluşlarını nitelemektedir (Yalçın, 2011, s. 24).

Kamu hizmetleri, hizmetlerin sunuluş kaynağına göre ikiye ayrılmaktadır. Bunlar milli ve mahalli kamu hizmetleridir. Milli kamu hizmetleri, ülke çapında, merkezi yönetim kuruluşları ile hizmet bakımından yerinden yönetim kuruluşları bünyesinde yürütülen kamu hizmetleridir. Mahalli kamu hizmetleri ise yerel yönetimlerin kendi sınırları çerçevesinde ve mahalli halkın ihtiyaçlarını karşılamak üzere yürüttükleri kamu hizmetleridir. Örneğin, Türkiye Cumhuriyeti Devlet Demir Yollarının sunduğu ulaştırma hizmeti milli bir kamu hizmeti, İstanbul Elektrik Tramvay ve Tünel İşletmeleri Genel Müdürlügünün sunduğu ulaştırma hizmeti ise mahalli bir kamu hizmeti sayılabilecektir (Karatoprak, 2010, s. 366). Kamu hizmetlerinin merkezi yönetim ya da yerel yönetimlerce verilmesi konusu, ülkeden ülkeye değişebilmektedir. Bunda, söz konusu ülkenin yönetim anlayışının merkeziyetçi olması ya da yönetimde yerel yönetimlere daha çok ağıllık vermesi durumları etki etmektedir. Devletlerin yönetim anlayışları da özellikle içinde bulunulan dönemin siyasi, sosyal ve ekonomik yönelimlerine göre değişebilmektedir (Çal, 2009). Örneğin, 20. yüzyılda batıda gelişen sosyal refah devleti anlayışıyla birlikte devletlerin sosyal hizmetlerde daha etkin olması görüşü, bunun bir yansıması olarak kamu kurumlarının büyümesi, çeşitlenmesi ve sayıca artması dolayısıyla yürütülen kamu hizmetlerinin de hacim olarak büyümesi ve çeşitlenmesi, bu hizmetlerin yürütülmesinde merkezi ve yerel yönetimlerin sorumluluk paylaşımlarına etki etmiştir. Bunun yanında, 1980'li yıllardan sonra etkisi büyüyen liberalleşme politikaları ve devletin küçülmesi anlayışı da kamu hizmetlerinin merkezi ve yerel yönetim kuruluşlarının yanında özel sektörce de yürütülmesi seçeneğini desteklemiştir (Sezer ve Vural, 2010, s. 204; Göker, 2016, s. 1740). Batıda, sosyal refah devletini benimsemiş ülkeler dahi bu etkiyle, kamu hizmetlerinin sunumunun bir kısmını özel sektör eliyle yürütmeye başlamış, sağlık hizmetleri, evde bakım hizmetleri, toplu taşıma ve sosyal güvenlik gibi önceki dönemlerde kamu sektörlerince yürütülen hizmetlerde özel unsurlar devreye sokulmuştur (Plantinga vd., 2011). Bu doğrultuda tekelli ve tekelsiz kamu hizmeti kavramları da karşımıza çıkmaktadır. Bir ülkede bir kamu hizmeti kamu kuruluşları yanında özel sektör kuruluşlarınca da yürütülüyorsa buna tekelsiz kamu hizmeti adı verilmektedir. Bunun yanında bir ülkede bir kamu hizmetinin özel sektörce yürütülmesi yasaklanmış ve bu kamu hizmeti sadece kamu kuruluşlarınca yürütülüyorsa, buna tekelli kamu hizmeti adı verilmektedir (Şen ve Acar, 2017, s. 148).

Kamu hizmetinden yararlanan kişilere göre kamu hizmetleri, bireysel yararlanma sunan kamu hizmetleri ve birlikte yararlanma sağlayan kamu hizmeti olarak ikiye ayrılmaktadır. Daha farklı bir boyutta, Altaban (2014, s. 201) kamu hizmetlerini hizmetlerin tüketim biçimi ve kentteki yerine bağlı olarak iki tür içinde sınıflandırmıştır. Bunlar başlangıç yerinde (tüketicinin bulunduğu yer) sunulan "dağıtım tipi" servisler ve bitiş yerinde (servisin bulunduğu yer) sunulan "servis tipi" hizmetlerdir. Servis tipi hizmetler, az sayıda başlangıç noktasından çok sayıdaki hedefe yönelik olarak yürütülmektedir. İtfaiye, emniyet hizmetleri ve çöp toplama hizmetleri gibi hizmetler buna örnek olabileceklerdir. Dağıtım tipi hizmetler ise çok sayıda başlangıç noktasından az sayıda hedefe yönelik hizmetlerdir. Okullar, kütüphaneler, hastaneler ve sosyal hizmet birimlerinde yürütülen hizmetler ise bu sinıfa giren hizmetlerdir. Diğer yandan her iki biçimin de görüldüğü gezici kütüphaneler, kan toplama hizmetleri gibi hizmetler de yürütülmektedir.

Son olarak konularına göre kamu hizmetleri idari, iktisadi, sosyal ve bilimsel-teknik-kültürel kamu hizmetleri olmak üzere dört başlık altında toplanabilecektir (Demir, 2013, s. 237). İdari kamu hizmetleri yönetimin verdiği ve kamu hukuku içinde yer alan genel hizmetlerdir. Kolluk kuvvetlerinin sağladığ1 koruma hizmeti bu hizmet türü kapsamında yer alan koruyucu idari hizmetlerdendir. İktisadi hizmetler, hem özel hem kamu hukuku sınırlarına giren endüstriyel ve ticari nitelikteki hizmetlerdir. Sosyal devlet anlayışı doğrultusunda gelişen sosyal hizmetler, vatandaşlara hak sağlayan, sosyal sağlık güvencesi gibi hizmetlerdir. Son olarak bilimsel, teknik ve kültürel hizmetler, vatandaşların bu alanlardaki ihtiyaçlarını karşılamak ve gelişimini desteklemek adına yürütülen hizmetlerdir (Odyakmaz, vd., 2009). Usta ve Bilgiç̧'in (2016, s. 252-252) aktardığ1 üzere, bu hizmetlerin sunulması ve yürütülmesinde üç aktör bulunmaktadır. Bunlar düzenleyen, üreten ve tüketen aktörlerdir. Hizmeti sunacak olan belediyeler ve yerel yönetim kuruluşları gibi kuruluşlar hizmetleri doğrudan kendileri sunabilecekleri gibi bu hizmetleri özel sektör kuruluşlarına da yaptırabilirler. Böyle bir durumda, hizmet sunumunda belediyeler ya da yerel yönetim kuruluşları düzenleyen, hizmet sunumunu yüklenen özel kuruluş üretken aktör olacaktır. Hizmet 
sunumundan yararlanan vatandaşlar ise tüketen aktördür. Kamu kuruluşu ve hizmeti yürütecek özel sektör kuruluşu arasında bir yetki denetim, finansman ve uygulama boyutlarında bir ilişki söz konusudur.

Kamu kuruluşlarının hizmet sunumunda farklı yöntemler vardır. $\mathrm{Bu}$ yöntemler, emanet, ihale/sözleşme, imtiyaz, yap-işlet devret, şirketleşme ve yönetimler arası ilişkiler/işbirliğidir. Emanet usulünde hizmet, araya herhangi bir başka kamu kurumu ya da özel sektör kuruluşu girmeksizin, belirli kurallar çerçevesinde direkt olarak kamu kuruluşunca sunulmaktadır. İhale/Sözleşme yönteminde kamu kuruluşu, sunulacak hizmeti bir sözleşme ile özel sektör kuruluşuna devretmektedir ve hizmet özel sektör kuruluşunca sunulmaktadır. Bazen söz konusu hizmet sadece tek bir özel kuruluşa verilerek tekel şeklinde sunulabilir. Bu yöntem imtiyaz yöntemi olarak adlandırılmaktadır. Yap-İşlet-Devret yöntemi ise son yıllarda yaygınlaşan bir yöntemdir. Bu yöntemde, kamuya ait taşınmazlar üstünde özel firmaların kamu hizmetini bir anlaşma karşıllğında, belirlenen süre boyunca sunması söz konusudur. Belirlenen süre bittiğinde işletmenin tüm varlıklan kamu kuruluşuna geri devredilmektedir. Bir diğer yöntem ise belediye şirketleridir. Belediyeler çeşitli kamu hizmetlerini sunmak üzere şirketler kurabilmektedir. Bu yöntem Yeni Kamu İşletmeciliği anlayışının (Ömürgönülşen, 2003) yerel yönetimlere yöntemsel bir yansıması olarak ele alınabilecektir. Son olarak Yönetimler Arası İşbirliği yöntemi, büyük ölçüde teknik bilgi ve uzmanlık gerektiren kamu hizmetlerinin sunulmasında hizmetinin doğrudan kamu kuruluşunun kendisi tarafindan değil, başka yönetimlerle ortak bir şekilde sunulmasını ifade etmektedir. Belediyeler bu konularda işbirlikleri yapabilmektedir. Söz konusu işbirliği aynı ülke içerisinde bulunan belediyeler arasında gerçekleşebileceği gibi farklı ülkelerde bulunan belediyeler arasında da yapılabilmektedir. İşbirliklerinin aynı ülke içerisindeki belediyeler tarafından uygulanması durumunda ulusal, farklı ülkelerde bulunan belediyeler tarafindan uygulanması durumunda ise uluslararası işbirliği söz konusu olacaktır (Öktem, vd., 2016, s. 51). Kamu hizmetlerinin sunumunda burada bahsedilen aktörlerden ayrı olarak gönüllü katılım esasına dayanan ve "Yerel yönetim hizmetlerine gönüllü katıllım" yöntemi olarak isimlendirilen bir yöntem de bulunmaktadır. Bu yöntemde sivil toplum kuruluşları (vakıflar, dernekler gibi) ve gönüllü kuruluşların kamu hizmetlerine yönelik katkı sağlaması amaçlanmaktadır. Böylelikle gönüllülük ilkesi kapsamında vatandaşlar bireysel olarak kamu hizmeti sunumunda yer alabilmektedirler (Eryllmaz, 2015, s. 217).

\section{Kamu Hizmeti Sunumunda Dönüşüm ve Dijitalleşme}

İçinde bulunulan dönemde ülkeler hızla bir dijital dönüşüme uğramaktadır. Bireyler, kurumlar, iş alanlar1 ve dahi nesneler, dijitalleşme yolunda hızla ilerlemektedir. Bu dijital dönüşümle birlikte bireylerin günlük yaşamları, çalışma biçimleri, alışkanlıkları ve değer yargıları değişime uğramaya başlamış ve günlük yaşamın neredeyse her alanında köklü değişiklikler meydana gelmiştir (ATDE, 2016). Her ne kadar ilk olarak 2015 yllında gerçekleştirilen Dünya Ekonomik Forumunda gündeme gelse de aslinda ilk olarak 2011 yılında Almanya Hannover Fuarında kullanılan Endüstri 4.0 terimi bu köklü değişimlerin açıklanmasında kullanılan ana başlıklardan birisi olmuştur. Dünya ekonomik forumunun kurucusu olan ve Endüstri 4.0 üzerine çalışmalar yapan $\mathrm{K}$. Schwab, bu devrimi üç temel bileşen etrafinda karakterize etmiştir. $\mathrm{Bu}$ bileşenler çok daha yaygın ve mobil bir internet, ucuzlayan, daha küçük ama daha güçlü algılayıcılar (sensörler) ve yapay zekâ ile makine öğrenmesidir. Schwab'a göre ülkeler için ilerlemenin başlıca ölçütü, inovasyonu kucaklama derecesi olacaktır (Schwab, 2017, s. 17'den akt. Atınışık, 2017, s. 1940). Dijitalleşmeyi bir ihtiyaç olarak gören ve onu olumlayan bir başka görüş olarak, Türkiye'nin en dijital şirketlerini belirleyen ve değerlendiren bir çalş̧ma olan Accenture Dijitalleşme Endeksi'nin (ATDE, 2015) verilerine göre, ülkedeki özel şirketlerin büyük bir bölümü dijitalleşmenin önemini kabul etmektedir. Davidsson ve arkadaşları (2016), söz konusu dijitalleşme sürecinin dört ayrı dalga şeklinde yayıldığını vurgulamışlardır. Birinci dalga 80'li yıllarda bilgisayarların topluma tanıtılması ile başlamışıtır. İkinci dalga, 90'll yıllarda bu bilgisayarların ve internetin kullanımının yayılması ile birlikte bilgiye erişimin de daha kolay bir hale gelmesini temsil etmektedir. Üçüncü dalga ise mobil internetin ortaya çıarak internete bağlanmanın mekândan bağımsız bir hale gelmesi ile ortaya çıkmıştır. Son olarak dördüncü dalga, internet kullanımının yalnızca insanlar tarafindan değil, araçlar, uygulamalar ve nesneler tarafindan da gerçekleştirilmeye başlamasını temsil etmektedir. Alan yazınında "nesnelerin interneti" olarak sıkça yer almaya başlayan terim de gelinen bu dönemin yansımalarından birisidir. İnsanların, sistemlerin, makinelerin ve diğer nesnelerin internet ve ağlar aracilığıly her zaman ve her yerde bağlı olabilmesini ifade eden bu kavram, çalısmanın bir sonraki bölümünde detaylı olarak ele alınacaktır.

Yukarıda ele alınan süreçler sonucunda gelişen bilgi, internet ve iletişim teknolojileri günlük yaşamın birçok alanına etkilerde bulunmuştur. İnsanlar birbirleriyle çok kolay ve çeşitli şekillerde iletişim sağlamaya başlamış (anlık mesajlaşmalar, görüntülü aramalar, hologramlı görüşmeler, video konferanslar), özel şirketler internet üzerinden ticarete yönelmiş, insanların alışveriş alışkanlıkları e-alışverişe yönelmiş, 
alternatif bir medya olan sosyal medya yaygınlaşmıştır. Kamu yönetimi de bu süreçten etkilenmiş, vatandaşlar ve kamu kurumları arasındaki etkileşim artmış, kamu kurumları bir takım kamu hizmetlerini internet ve internet tabanlı çeșitli aplikasyonlar üzerinden vermeye başlamıștır. Bu gelișmeler öncelikli olarak kamu kurumlanı ile vatandaş arasındaki iletişimin internet, mobil cihazlar ve sosyal medya ile gelişmesi ve kamu kurumlarının kamuyu bilgilendirme kanallarını internet ortamına taşıması şeklinde gözlemlenmiştir. Bunun ötesinde ise kamu kurumları internet üzerinden hizmet vermeye başlamıştır. Kütüphaneler vatandaşlara internet üzerinden kaynak taramaları, ödünç alınacak kitaplar için rezerve yapma imkânı gibi çeşitli hizmetler sunmaya başlamışlardır. Önceki yıllarda kamu kurumlarına gidilerek alınan hizmetlerden olan adli sicil kaydı alma, mezuniyet belgesi alma, nüfus örneği alma, vergi ödeme gibi birçok hizmet, artık vatandaşlar için evde bilgisayar başında alınabilir hizmetler haline gelmiştir. Merkezi yönetim ve yerel yönetimlerde sosyal medya ve çeşitli platformlarda siyasal katıllımı geliştirmek üzere uygulamalar geliştirilmektedir. Kamu kurumları, vatandaşlar ve nesnelere ait sınırsız bilginin işlenebilir ve çeşitli amaçlarla kullanılabilir hale getirildiği büyük veri kamu yöneticileri ve kamu politikacıları için daha iyi politikalar üretmede araç olmaya başlamıştır (Gül, 2018, s. 13).

Kamu yönetimi alan yazınında, kamu hizmetlerinin sunumunda gerçekleşen dijital dönüşümün en somut hali olarak e-devlet uygulamaları gösterilmektedir. Alan yazınında e-devleti "bir kurtarıcı" ya da kamu yönetiminin mevcut tüm sorunlarının çözümü için "sihirli bir değnek" olarak gören ya da kavramı sınırlı ve yüzeysel olarak tanımlayan araştırmacılara rastlamak mümkündür (Mecek, 2017, s. 1818). İnsan tasarımı ve geliştirmesi ile var olan e-devletin etki ve imkân sınırlarını da temelde insan belirlediği için, edevlet sihirli bir değnek ya da kurtarıcıdan ziyade, kamu hizmet sunumunun kalitesinin çok boyutlu olarak artması için geliştirmeye çok açı bir araç olarak görülebilecektir. Zira e-devlet uygulamaları kamu hizmetlerine ilișkin bilgilerin kamu kuruluşlarında, internet siteleri ve çeșitli dijital platformlardan açık erişim esasına dayalı olarak vatandaşlarla paylaşılması şeklinde ortaya çıkmışır. Erişime Açık Kamusal Bilgi (Open Government Data) olarak isimlendirilen bu uygulama ile birlikte kamuya ilişkin bilgiler kamu kurumları tarafından erişilebilir, makineler tarafından okunabilir, insanlar tarafından anlaşıabilir ve diğer taraflarca kamu hizmetlerine uygun doğrultuda revize edilerek dağıtılabilir hale gelmiştir (Mergel vd., 2018; Roy, 2017, s. 539). Söz konusu hizmetler merkezi yönetimlerin yanında yerel yönetimler tarafindan da kullanılmaya başlanmışır (Schou ve Hjelhot, 2018). Bu doğrultuda e-devlet için uygun tanımın, teknoloji, gelişme ve kamu hizmetlerinin iyileştirmesi unsurlarını bir araya getirecek bir tanım olacağı düşünülmektedir. Öyleyse e-devlet, gelişen bilgi teknolojilerinin sunduğu tüm imkanları kullanarak, devletin vermesi gereken kamu hizmetlerinin daha hızlı, etkili ve verimli sunması ve aynı zamanda vatandaşın da devlete karşı olan yükümlülüklerini ve kamusal işlemlerini daha kolay ve hızlı bir şekilde, kesintisiz ve güvenli bir şekilde yerine getirebilmesi projesidir (Özer ve Otyzbay, 2018; Tunç vd., 2017). E-devletin üzerinde mutabık kalınan güncel amaçları, vatandaşların kamu hizmetlerine daha kısa zamanda, daha kolay ulaşması, işlem maliyetlerini düşürmek, bürokratik süreç ve külfetleri azaltmak şeklinde sıralanabilir (Negiz ve Saraçbaşı, 2012, s. 51; Ünal ve Kiraz, 2016, s. 440). Söz konusu amaçların "güncel" şeklinde vurgulanmasının nedeni kamu yönetiminde yaşanan dijital dönüşüm sürecinde kamu hizmetleri ve sunumlarına dair yeni ihtiyaçların (Lindgren ve Veenstra, 2018) ortaya çıkabilecek olmasıdır.

E-devlete ilişkin çalışmalar son yıllarda yükselen bir ivme kazansa da bu çalışmaların temellerinin 1990’lı yılların sonlarında atılmaya başlandığını söylemek yanlış olmayacaktır (Kaya ve Mursül, 2017). Avrupa'da Avrupa Komisyonu, Türkiye'de ise devlet planlama teşkilatının e-devlet çalışmaları, "elektronik devlet başlğ̆ ile sunulmuştur. İçinde bulunulan dönemde e-devletin geldiği noktayı geçmişten yola çıkarak değerlendirmek ve bu temelde geleceğe dair projeksiyonlarda bulunmak, isabetli öngörüler sağlamak adına doğru bir yol olabilecektir. Bu doğrultuda İnce'nin (2001) Devlet Planlama Teşkilatı (DPT) bünyesinde yayınlanan çalışması, e-devleti geçmişte araştırmak adına önemli fikirler vermektedir. Yazar, e-devletin bir alt sistemi olarak ele aldığı "kamu bilgi otoyolu" sisteminin üç tür hizmet sağlayacağını ve bu hizmetlerin bilgi verme hizmetleri (tek yönlü), iletişim hizmetleri (çift yönlü) ve on-line işlem hizmetleri (tek ya da çift yönlü) olacağını vurgulamıştır. Çalışmada ayrıca Avrupa Komisyonunun e-devlette yer alacak olan elektronik kamu hizmetleri kullanım alanlarını belirlediği tabloya yer vermiştir. Söz konusu tablo şu şekildedir: 


\begin{tabular}{|c|c|c|c|}
\hline & Bilgi Verme Hizmetleri & İetissim Hizmetleri & On-line Isslem Hizmetleri \\
\hline Günlük Yaşam & $\begin{array}{l}\text { *İş hayat1, } \\
\text { *Konut, } \\
\text { *Ĕğitim, } \\
\text { *Sağlık, } \\
\text { *Kültür, } \\
\text { *Ulaşım, } \\
\text { *Çevre vs. hakkında bilgiler }\end{array}$ & $\begin{array}{l}\text { *Günlük yaşama ilişkin } \\
\text { konularda danışmanlık } \\
\text { *İş ya da konut ilanları } \\
\text { *Elektronik posta } \\
\text { İletişimi }\end{array}$ & $\begin{array}{l}* \text { Bilet rezervasyonu } \\
{ }^{*} \text { Çeşitli programlara kayıtlar }\end{array}$ \\
\hline $\begin{array}{l}\text { Uzaktan } \\
\text { Yönetim }\end{array}$ & $\begin{array}{l}\text { *Kamu hizmetleri rehberi } \\
\text { *İdari süreçler için kılavuz } \\
\text { *Kamu kayıtları ve veri } \\
\text { tabanları }\end{array}$ & $\begin{array}{l}\text { *Kamu görevlileri ile } \\
\text { elektronik posta iletişimi }\end{array}$ & $\begin{array}{l}* \text { Formların elektronik } \\
\text { ortamda doldurulmas1 }\end{array}$ \\
\hline Politik Katılım & $\begin{array}{l}\text { *Yasal düzenlemeler } \\
* \text { Meclis kayıtları } \\
\text { *Siyasi programlar } \\
\text { *Görüş belgeleri } \\
\text { *Karar alma sürecinde } \\
\text { hazırlanan belgeler }\end{array}$ & $\begin{array}{l}\text { *Siyasi konulara ilişkin } \\
\text { tartışmalar } \\
\text { *Politikacılarla elektronik } \\
\text { posta iletişimi }\end{array}$ & $\begin{array}{l}* \text { Referandum } \\
* \text { Seçimler } \\
* \text { Anketler }\end{array}$ \\
\hline
\end{tabular}

Kaynak: Avrupa Komisyonu, 1998

Tablo 1'de görüldüğü üzere e-devletin, bu dönemde geldiği noktanın temellerinin büyük bir kısmı henüz 1990'ların sonunda karakterize edilmiştir. Günlük yaşamdaki kamu hizmetlerine ilişkin öngörülerin tamamı gerçekleşmiş ve bunlara ek olarak, on-line alışveriş, ödeme, eş zamanlı teknik destek, sağllk randevusu alma vb. gelişmiş hizmetler sunulmaktadır. Uzaktan yönetimde, kamu görevlileri ile iletişim sadece elektronik postalarla sınırlı kalmamış e-devlet platformları, sosyal medya, video konferanslar vb. uygulamalarla hizmetler geliştirilmiştir. Kamu hizmetlerine ilişkin formların elektronik ortamda doldurulmasından öte, vatandaşlara ilişkin devlet bilgi tabanında yer alan bilgilerin elektronik formlarla vatandaşa sunulması, yeni resmi belgeler oluşturulması, cep telefonları üzerinden birçok kamu hizmetinden faydalanabilmesi (Yıldız, 2006) gibi hizmetlere geçiş yapılmıştır. Politik katılımda, çalışmada "uç nokta" olarak vurgulanan seçimlerin, referandumların ve anketlerin elektronik ortamda yapılması uygulamaları günümüzde kullanılmaya başlanmış uygulamalardır (Akın, 2006; EP, 2016). Öngörüler düşünüldüğünde, edevletin çalışma ve raporda tahmin edilenden daha hızlı bir gelişme gösterdiği kanısına varılabilmektedir. Kamu hizmetlerinin dijitalleşmesine yönelik geçmişteki beklentilerin gözlemlendikten sonra, bu hizmetlerin gelişimini ve geleceğe dair bugünkü projeksiyonlarını ele almak, süreci daha iyi anlayabilmek adına isabetli olacaktır.

Bertot ve arkadaşları (2016), dijitalleşen, inovatif kamu hizmetlerinin şeffaf, katılımcı, ileriye yönelik, kişiselleşmiş, işbirlikçi ve şartlara duyarlı olma ilkeleri doğrultusunda gelişmesi gerektiğinin altını çizmektedir. Kamu hizmetlerinin dijitalleşme sürecini inceleyen yazarlar, dijital devletin kamu hizmetlerinin bu süreçte geçirdikleri evreleri Tablo 2'de gösterilen şekilde özetlemişlerdir.

Tablo 2. Dijital Devletin Evreleri

\begin{tabular}{cc}
\hline Evreler & Uygulama Bă̆lamı \\
\hline Dijitalleşme & Teknolojinin Kamu Sektörüne Girişi \\
Dönüşüm & Teknoloji Etkisinde İdari Yapilanma \\
Bütünleşme & Teknoloji Etkisinde Kamusal Aktörler \\
Bir Bağlam İçine Girme & Teknoloji Etkisinde Sektörler ve Toplumlar \\
\hline
\end{tabular}

Kaynak: Bertot vd., 2016'dan uyarlanmıştır

Eggers ve Macmillan (2015), Kamu 2020: Kamunun Geleceğine Yolculuk başlıklı raporda (Deloitte) dijital devrimin dört temel teknolojinin kesişim alanından meydana geldiğinin altını çizmişlerdir. Bu teknolojiler sosyal, mobil, analitik ve bulut teknolojileridir. Bu teknolojiler sayesinde bireyler ve kamu kuruluşları gelişmiş analitik yöntemler ve duygu analizleri kullanarak kitlelerin gücünü kullanmaya başlamış ve sosyal ağlar günlük yaşamın her alanına girmişlerdir. Giyilebilir teknolojiler ve mobil cihazların kullanımı yaygınlaşmış ve bu ürünler insanları ve nesneleri her an bağlantılı bir hale getirmiştir. Rapora göre, dijitalleşme ile birlikte kamu hizmeti anlayışında yedi köklü değişiklik gerçekleşmiştir. Bu değişiklikleri aşağıdaki gibi özetlemek mümkündür (Eggers ve Macmillian, 2015): 
- Cö̈züm sağlayzı kamu kuruluslarn yerine imkân sağlayan kamu kuruluşlar: Buna göre en başarılı kamu kuruluşları, kamusal problemlere karşı çözümleri kendileri aramak yerine, çözüme yönelik aktörleri bir araya getirerek, toplumsal çözümler üretmeye yönelik adımlar atmaktadırlar. Bu doğrultuda kamu kurumları özel sektör şirketleri arasında çözüme yönelik rekabet sağlayabileceği gibi kamu-özel işbirliklerine de başvurabilmektedir.

- Kisize özel bizmet sunumu: Gelişen mobil teknolojiler sayesinde sunulan kamu hizmetleri de kişiselleşmektedir. İhtiyaçları farklılaşan yerel yönetimlerde, hedef kitleye yönelik farklılaşmış dijital uygulamalarla hizmet sunulabilecektir. Örneğin, avcllık faaliyetlerinin yoğun olduğu bir ilçede, kamu kurumunca avcılık belgesi doğrulama mobil uygulaması geliştirilmesi gibi.

- Dă̆gtık yönețisim: Dijitalleşmenin gelişmesine bağlı kamu yöneticilerinin vatandaşlarla daha kolay sorumluluk paylaşabilmesini ifade etmektedir. Örneğin, Hawaii'nin tsunami felaketine karşı uyarı uygulamasında, gönüllülük esasına dayalı olarak, vatandaşlar uyarı sirenleri satın alarak kendi aralarında koordineli bir şekilde felakete karşı siren nöbeti tutabilmektedirler.

- Veri konusunda akillıca davranan kamu kurulussu: Dijitalleşme ile birlikte gelişen veri analizi ve sunum sistemleri sayesinde analitik verilerden yararlanılarak daha etkili ve verimli kararlar alınabilmektedir.

- Kamu kuruluslarmnn finansmannna yönelik alternatif modeller. Gelişen teknoloji ile birlikte kamu kuruluşları, vatandaşların belirli bir ücret karşılığında faydalandığı hizmetlerin fiyatlandırmasında daha hassas modellere geçebileceklerdir. Çeşitli hizmetler için dinamik fiyatlandırma seçenekleri söz konusu olabilecektir.

- Kamuda ibtiyaca göre bizmet modeli: Teknolojinin insan kaynaklarında da kullanılması ile birlikte kamu kurumlarında ihtiyaca göre projeler arası geçiş esasına dayanan insan kaynağı yönetimine geçiş yapilabilecektir.

- Ulusal refahın yeni zemini: Gelişen teknoloji ve dijitalleşme sonucunda ulaşılacak yeni veri toplama ve değerlendirme yöntemleri ile birlikte kişisel güvenlik, ekosistemlerin sürdürülebilirliği, sağlık ve afiyet, barınma, shhhi sistemler, katılım ve kişisel özgürlük yeni ölçütlerin eklenmesiyle daha bütüncül bir ulusal refah zemini sağlanabilecektir.

Raporda (Eggers ve Macmillian, 2015) ayrıca çeşitli kamu hizmetlerinin geleceklerine dair spesifik projeksiyonlarda bulunulmaktadır. 2020 yllında kamu hizmetleri sunumundaki dijitalleşmeye bağlı değişimler olacaktır. Eğitimde Sanal öğrenim, sayısallaştırma ve artırllmış gerçeklik ile birlikte geleneksel sınıf yapısı değişime uğrayacaktır. İnteraktif ve dinamik bir eğitim anlayışıyla proje bazlı eğitimler teşvik edilecektir. Enerji sektöründe akıllı aygttlar ve sensörlerle birlikte enerjiyi daha tasarruflu, verimli ve etkili kullanmanın yolları açılacak, verilere dayalı daha iyi bir yönetim sağlanacaktır. Sağlık alanında, mobil uygulamalar, giyilebilir ve yutulabilir teknolojilerle birlikte hastalara dair daha iyi bir veri akışı sağlanacak ve daha iyi bir hizmet sunumu yapılacaktır. Söz konusu veri akışı sosyal hizmet alanında da kullanılarak bireylerin ihtiyaçlarına yönelik bireysel hizmet sunumları gelişecektir. İnsansız hava araçları, suçlu analiz uygulamaları, mobil-sanal kelepçe uygulamaları gibi uygulamaların gelişmesi ile birlikte hukuk alanında dijital dönüşüm devam edecektir. Ulaşım alanında ise dijital sinyallere dayalı toplu ulaşım sistemleri, sürücüsüz otomobiller, self-servis havaalanları, mobil cihaz destekli ulaşım sistemleri gelişmeye devam edecektir. Web 2.0 araçlarının sağladığı imkanlar ile (Göçoğlu, 2014, s. 33) vatandaşların kamu politikalarına e-katılımı daha fazla sağlanacak ve böylelikle kamu yönetiminin şeffaflığı arıtılabilecektir (Erkul, 2009, s. 3; Xiangxuan, 2017). Diğer yandan kamu hizmetlerinin sunumunda yaşanan tüm bu dijital dönüşüm ve gelişmeler ile birlikte yaygınlaşan internet ve ağ kullanımları, bunları kullanacak olan vatandaşların ve kamu görevlilerinin söz konusu donanım ve yazılımları kullanabilme yeteneklerini (Barth ve Veith, 2011) vatandaşların bireysel ve kamu kuruluşlarının da kurumsal bilgi güvenlikleri konularını önemli bir hale getirmektedir (WhitePaper, 2017, s. 6; Chunquan ve Shunbing, 2012). Bu durum, dijitalleşen kamu hizmetlerinde uygulama eğitimleri, siber güvenliğin sağlanması gibi farklı konularının diğer akademik çalışmalarının odağı haline getirmektedir.

Kamu yönetiminde dijitalleşme ile yaşanan bu dönüşümler ve öne çıan konuların Türkiye'de tartışıldığı en geniş platform KAYFOR 8 ve KAYFOR 15 (Kamu Yönetimi Forumu) olmuştur. Kamu Yönetimi ve Teknoloji ana temasıyla gerçekleştirilen 8. KAYFOR'da teknolojinin kamu yönetimine etkileri ve yansımaları çoğunlukla olumlu bir bakış açısıyla ele alınmış, ortaya çıkan ya da çıkabilecek negatif dışsallıklar görece sınırlı olarak ele alınmıştır (Alınışık, 2017, s. 1938). Dijital Çağda Kamu Yönetimi ve Politikaları ana teması etrafında gerçekleştirilen 15. KAYFOR'da ise kamu yönetiminde dijitalleşmeye ve 
dijitalleşmenin boyutlarına karşı daha eleştirel bir bakış açısı geliştirilmiştir. Bu bölümde ve ilgili alan yazınında genel olarak kamu yönetiminde dijital dönüşümün sağladığı faydalarının ve sağladığı kolaylıkların ön planda tutulmasına karşın, bu dönüşümün ortaya çıkardığı negatif dışsallıklarında odak olarak alındığ1 "antitez" niteliğinde yapılacak çalışmalar da, çalışma alanının gelişsimine katkıda bulunmaları açısından önem arz etmektedir.

\section{Nesnelerin İnterneti ve Kamu Hizmetleri Sunumunda Kullanılması}

Son dönemlerde kamu yönetimi alan yazınında sıkça geçen bir kavram olan nesnelerin interneti (İngilizce, Internet of Things; kısaca, Io'T), milyonlarca insan ve nesnenin internet ağıyla birbirine bağlı olduğu, düzenli olarak bilginin üretildiği, analiz edildiği ve çeşitli amaçlarla kullanılmak üzere paylaşıldığ1 bir dünyayı ifade etmektedir. Bu dünyada birbirine bağlı olan şeyler sadece bilgisayarlar değil, makineler, taşıtlar, akıllı telefonlar, ev aksesuarları, giyilebilir teknolojiler, oyuncaklar, kameralar, sağlık ekipmanları, hayvanlar, insanlar, binalar ve hatta şehirlerdir (Patel ve Patel, 2016, s. 6122). Birbirlerine bağlı olan söz konusu unsurlar genellikle son teknoloji donanım ve yazılımlarla geliştirilmiştir. Algıllayıcı çeşitli sensörler yardımıla nesneler birbirlerinden haberdar haldedir ve çeşitli programlamalar sonucunda belirli amaçlar doğrultusunda birbirleriyle etkileşim içindedirler (Gunashekar vd., 2016; Bhoomika vd., 2016). Söz konusu etkileşimli sistemler ilk olarak Küresel Konumlanma Sistemi (İngilizce, Global Positioning System; kısaca, GPS) teknolojisi ile gelişmeye başlamışır. Bu teknoloji ile cihazlar ve taşıtlar bilgisayarlar ve mobil telefonlar ile takip edilebilir hale gelmiştir (Ramamurthy ve Jain, 2017, s. 3). Nesnelerin internetinde yaşanan gelişmeler ve bu teknolojiye uyum sağlayacak şekilde yön alan yeni ürünler hem özel sektör hem de kamu sektörünün ilgisini çekmiştir. Özel şirketler yönetim süreçlerinde, üretim biçimlerinde ve ürünlerinde nesnelerin internetini odak almaya başlamış, kamu yönetimi ise sokak aydınlatmaları, otoparklar ve trafik yönetim sistemlerinden su yönetimi, enerji yönetimi, çevre denetimi sistemlerini kadar birçok sistemi akıllı ve nesnelerin internetine uygun olarak bağlantılı bir hale getirme çabasına girmişlerdir (Huawei, 2018, s. 2).

Nesnelerin internetini anlamak için onu meydana getiren teknolojileri ele almakta yarar vardır. Zheng ve arkadaşları (2011), nesnelerin internetini oluşturan anahtar teknolojileri mimari modeller, ağ ve iletişim, arama ve keşfetme motorlan, gizlilik ve güvenlik, uygulama ve endüstriyel dağıtım, yönetişim ve sosyoekonomik ekosistem teknolojileri olarak sıralamışlardır. Mimari modeller nesnelerin internetinin ana sütunlarını oluşturmaktadır. Sistemin teknik altyapısına odaklanan yatay, uygulama ve yayılmasına odaklanan dikey boyutları vardır. A $\breve{g}$ ve iletişim teknolojileri nesnelerin birbirine bağlanması uygulamalarına odaklanmaktadır. Arama ve keşfetme motorları, nesnelerin birbirlerini bulması, tanıması ve iletişime geçmesi fonksiyonlarını geliştirmektedir. Gizlilik ve güvenlik teknolojiler, birbirleri ile bağlantıda olan nesneler arası bilgi üretimi, paylaşımı ve depolamasının güvenliğini mercek altına almaktadır. Uygulama ve endüstriyel dağıtım, bu teknolojinin uygulanacağı ve kullanılacağı alan ve sektörler üzerine odaklanırken, son olarak yönetişim ve sosyo-ekonomik ekosistem teknolojileri ise sistemin yönetişim, finansman, hukuki düzenlemeler gibi sosyal boyutları üzerine odaklanmaktadır. Burada, nesnelerin internetinin kamu hizmetlerine yayılmasının hangi temellere dayandığını görmek için sistemin ana sütunlarını oluşturan mimari modellere odaklanmak gerekmektedir. Yazarların çalışmalarında yer verdikleri şema bu modelleri iyi bir şekilde tasvir etmektedir. Söz konusu şema tablo, aşağıda, Tablo 3’te yer almaktadir.

Tablo 3. Nesnelerin Interneti Mimari Modelleri

\begin{tabular}{clll}
\hline \multirow{2}{*}{$\begin{array}{c}\text { Uygulama } \\
\text { Katmanı }\end{array}$} & $\begin{array}{l}\text { Akıllı Trafik, Gıda } \\
\text { İlenebilirliği }\end{array}$ & Çevre Üretimi, Sektörü İzleme & Servis Alt Katmanı \\
\cline { 2 - 4 } & $\begin{array}{l}\text { Akıllı Süreç, Servis Destek } \\
\text { Platformu }\end{array}$ & $\begin{array}{l}\text { Bulut Teknolojisi, Ara Katman } \\
\text { Teknolojisi }\end{array}$ & Destek Alt Katmanı \\
\hline Ăg Katmanı & 2.5G-3G-4G, İnternet & W-Lan, GPS & IP \\
\hline \multirow{2}{*}{$\begin{array}{c}\text { Algılama } \\
\text { Katmanı }\end{array}$} & WSN, Ad-hoc sistemleri & $\begin{array}{l}\text { Koordinasyon Onarıc1 } \\
\text { Teknoloji, Ara Katman }\end{array}$ & İsbirliği \\
& & Teknoloji & \\
\cline { 2 - 4 } & Sensör, RFID, URB sistemleri & NFC, WiFi, Camera & Bilgi Edinme \\
\hline
\end{tabular}

Kaynak: Zheng vd., 2011, s. 142'den uyarlanmıştır 
Tablo 3’te yer alan şemanın ilk katmanında nesnelerin internetinin etkide bulunduğu alanlardan ikisi örnek verilmiş ve uygulamaların servis ve destek altyapısında yer alan bulut teknolojisi ve değişebilir olan ara katman teknolojinin altı çizilmiştir. Bu katmanda yer alan, nesnelerin interneti ile birlikte akıllı hale gelmiş olan trafik, gıda izleme uygulama örnekleri, akıllı şehirler, akıllı enerji üretimi ve dağıtımı, akıllı ulaşım, akıllı binalar, akıllı sağlık hizmetleri, akıllı lojistik ve akıllı katılım gibi sistemlerle çoğaltılabilecektir (Vermesan ve Friess, 2014). İkinci olarak ağ katmanı, nesneler arasında kurulan iletişimi sağlayan ağ1 oluşturan internet bağlantı ve ağ tiplerini içermektedir. Son katman ise nesnelerin birbirlerini ve kendilerine kullanıcılar tarafından çeşitli amaçlar doğrultusunda verilen komutları tanımalarını sağlayan sensör, RFID, URB,WiFi,kamera gibi sistemleri içermektedir. Tüm bu katmanlar, donanım ve sistemler, nesnelerin internetinin oluşumunu, altyapısını ve uygulamasını özetlemektedir.

Nesnelerin interneti, kamu yönetiminde dijital dönüşümü gerçekleştiren aktörlerden biridir. Sahip olduğu teknolojik imkanlarla yönetimlere daha etkin, etkili ve verimli kamu hizmeti sunma avantaj1 sağlamaktadır (Castro vd., 2016). Teknoloji devlerinden birisi olan Alcatel, yayınladığı raporda, nesnelerin internetinin kamu hizmetlerinin sunumunda, beş boyutta çeşitli avantajlar sağlayacağını belirtmiştir (Alcatel, 2018). Raporda belirtilenlere göre, ilk olarak vatandaşlar ve kamu kurumları arasında daha iyi bir iletişim sağlayarak kamu kurumlarının daha kaliteli, güvenli ve sürdürülebilir hizmetler sunmasını sağlayacaktır. Yerel yönetimler, kentlerdeki bilgi akışı ve kent işleyişini sensörler ve monitörleme sistemleriyle sürekli olarak kontrol altında tutarak, toplu taşıma araçlarını, yolların durumunu izleyerek vatandaşlara güvenli bir kent hayatı hizmeti verebilecektir. Akıllı şehirler ile birlikte enerji yönetimi, daha iyi bir arz-talep analizi ile tasarrufa yönelik olarak gerçekleştirilebilecektir. Gelişmiş ve proaktif izleme sistemleri ile birlikte hizmet sunumları daha hızlı ve işlem maliyetinden tasarruf edilmiş şekilde verilebilecektir. Son olarak, bu sistemler sayesinde kentlerdeki acil durumlar ve kriz durumlarına daha ani müdahale edilebilecektir. Amerikan Ulusal İletişim ve Bilgi Yönetimi Kurumu'nun (İngilizce, National Telecommunications and Information Administration; kısaca NITA) raporunda ise nesnelerin interneti ile dönüşebilecek bazı spesifik kamu hizmeti iyileştirmelerine yer verilmiştir. Bunlar, sensörler ve WiFi desteği sayesinde dolan çöp kutularının anlık tespiti ile atık yönetiminin verimlileşmesi, elektrik ve su dağıtım kanallarındaki sızıntıların sensörler ile tespit edilmesi suretiyle tasarruf sağlanması, GPS ile yönlendirilen itfaiye ve ambulans hizmetleriyle kamu hizmetleri sunumunda zaman tasarrufu sağlanması gibi hizmet iyileştirmeleridir. Takagi ve Mima (2016), sensör teknolojileri üzerine odaklanarak bu teknolojilerin kamu politikası üretim sürecinde yer alan probleme ilisskin bilgi toplama, değerlendirme, uygulama ve politikanın geliştirilmesi aşamalarında etkin olarak kullanılabileceğinin altını çizmişlerdir. Araçlara sensörler takılarak otomobil kullanım sıklığına göre kişilere özel motorlu taşıtlar vergisi hesaplanması ve tahsil edilmesi buna bir örnek olarak verilebilecektir. Daha genel ve önemli bir örnek olarak, nesnelerin internetinde anahtar teknolojilerden birisi olan sensör teknoloji sayesinde doğal çevre daha düzenli bir şekilde kontrol altında tutulabilecek, çevre kirliliği ve iklim değişikliği ile daha etkin bir mücadele yürütülebilecektir (Govloop, 2016). Maissin ve arkadaşlarının (2015) nesnelerin internetinin kamu hizmetlerini nasıl etkileyeceğini ele aldıkları çalışmada da çeşitli kamu hizmeti alanlarına dair gerçekleşmeye başlamış ve beklenen dönüşümlerin altı çizilmiştir. Yazarlara göre bu teknoloji ile birlikte aşağıda, tablo 4'de yer alan kamusal hizmetlerde yanlarında verilen örnekler doğrultusunda dönüşümler yaşanacaktır. 
Tablo 4. Cessitli Kamu Hizmetleri Alanlar ve Nesnelerin Interneti

\begin{tabular}{|c|c|c|}
\hline Kategori & Alt Kategori & Önnek \\
\hline Ulaşım & $\begin{array}{c}\text { Toplu Ulaşım } \\
\text { Trafik } \\
\text { Kamusal Bisikletler }\end{array}$ & $\begin{array}{l}\text {-GPS teknolojisi sayesinde toplu taşıma yapan } \\
\text { taşıtlar eş zamanlı olarak izlenecek ve bekleme } \\
\text { süreleri net belirlenebilecektir. } \\
\text {-Ulaşım kartı kullanımları anlık ve lokasyon } \\
\text { bazında izlenerek lokasyonlardaki yolcu } \\
\text { yoğunluğu belirlenebilecektir. } \\
\text {-Sensör teknolojisi ile daha iyi bir trafik yönetim } \\
\text { sistemi gelecektir. } \\
\text {-GPS teknolojisiyle kamu bisikletlerine hangi } \\
\text { lokasyonlarda daha çok ihtiyaç duyulduğu } \\
\text { belirlenebilecektir. }\end{array}$ \\
\hline Ekonomi & $\begin{array}{l}\text { Turizm } \\
\text { Endüstri }\end{array}$ & $\begin{array}{l}\text {-İzleme teknolojileri ile birlikte turistlere gittikleri } \\
\text { yerler hakkında daha kapsamlı bilgi } \\
\text { verilebilecektir. } \\
\text {-Endüstride, akıllı binalar hizmete sunulacaktır. }\end{array}$ \\
\hline Sağhlk & $\begin{array}{c}\text { Vatandaşa Yardım } \\
\text { Otomatik İlaç Hizmeti } \\
\text { Medikal Cihazların Onarımı }\end{array}$ & $\begin{array}{l}\text {-Acil durum butonu ile her vatandaş acil yardım } \\
\text { çağrısında bulunabilecektir. } \\
\text {-Kalp ve şeker hastalarında otomatik ölçüm } \\
\text { yapan sensörler, doktorlara bilgi yollayacak ve } \\
\text { doktorlar hastaya gerekli ilaç hizmetini } \\
\text { sunacaklardır. } \\
\text {-Sensörler sayesinde batarya ömürleri biten } \\
\text { cihazlar ilgililere batarya değişimi için sinyal } \\
\text { yollayabilecektir. }\end{array}$ \\
\hline Çevre & $\begin{array}{l}\text { Su Desteği } \\
\text { Kirlilik }\end{array}$ & $\begin{array}{l}\text {-Sensörlerle su hatlarındaki sızıntılar tespit } \\
\text { edilebilecektir. } \\
\text {-Sensörlerle bölgesel hava kirliliği } \\
\text { belirlenebilecektir. }\end{array}$ \\
\hline Yönetim & Elektronik Kimlik Belirleme Cihazı & $\begin{array}{l}\text {-Vatandaşa takılacak sihirli bilekliklerde kişilerin } \\
\text { bilgileri saklanacak ve kimlik hırsızlığının önüne } \\
\text { geçilebilecektir. }\end{array}$ \\
\hline Güvenlik & Dronlar & $\begin{array}{l}\text {-Dronlar kentleri izleyerek güvenlik sorunlarını } \\
\text { tespit edebileceklerdir. } \\
\text {-Duman sensörleri acil durumlarda müdahale } \\
\text { ekiplerine haber verebilecektir. } \\
\text {-Sensörlerle gaz hatlarındaki tehlikeler } \\
\text { önlenebilecektir. }\end{array}$ \\
\hline
\end{tabular}

Kaynak: Maissin vd., 2015

Tabloda yer alan kategorilerin alt kategorilerini literatürden çeşitli kaynaklardan genişletmek mümkündür. Ulaşım alanında, sensör ve GPS teknolojisi ile birlikte caddelerin trafik yoğunlukları izlenerek, trafik 1şıklarının bekleme süreleri trafik yoğunluklarına göre değiş̧tirilebilmektedir (Brous ve Janssen, 2015). Bu teknolojinin kullanıldığ bir kent olarak Vietnam'ın Da Nang kenti buna örnek olarak verilebilecektir (El-haddadeh vd., 2018). Vatandaşlara mobil aplikasyonlar aracilığıyla sunulacak hizmetlerle birlikte vatandaşlar, ilgili yönetimlere yolculuk deneyimleri ile ilgili geri bildirimde bulunabileceklerdir (GOS, 2014). Çevre kategorisinde yer alacak önemli alt kategorilerden biriside tarımdır. Nesnelerin interneti tarım alanında kullanılmaya başlamıştır. Toprağın sahip olduğu su miktarı sensörler yardımıyla ölçümlenerek, toprağın suya ihtiyacı olduğu durumlarda, ihtiyaç oranında sulama yapılabilmektedir. Tarıma dayalı gıdaların tazelikleri ve sağlık açısından durumları henüz tarlada ve hasattan sonra depolama alanlarında kontrol altında tutulabilecektir. Sağlık alanında, belirli şikayetleri neticesinde hastalığı teşhis edilemeyen hastalar, sensörler ile birlikte izlemeye alınarak, erken teşhisler mümkün hale gelebilecektir (GOS, 2014). Güvenlik kategorisinde, kamu güvenliği konusunda çeşitli sivil toplum kuruluşları ve vatandaşlar görevlendirilerek kendilerine kamu güvenliğine ilişkin hususları bildirmek amacıyla GPS donanımlı cihazlar verilebilecektir. Bu sayede kolluk kuvvetlerinin olay yerinde olmadığı durumlarda, vatandaşlar kamu güvenliğini korumak amacıyla kolluk kuvvetlerine anlık bildirimlerde bulunabileceklerdir (Kantarc1, 2014, s. 360). Bunun yanında ulusal güvenliğin söz konusu olduğu durumlarda, devletin fiziki ya da siber sahalarına giren tehditleri tespit etmek amacıyla da amaca yönelik gelişmiş sensör teknolojileri kullanılabilecektir (Fraga-Lamas vd., 2016). Tüm bu yönleriyle nesnelerin interneti, kamu yönetiminin ve kamu hizmetlerinin çeşitli alanlarında çeşitli amaçlara yönelik olarak yönetimlere büyük avantajlar sağlayacaktır. 


\section{Tartışma, Sonuç ve Öneriler}

Son yillarda yaşanan teknolojik gelişmeler ve yayılan internet bağlantılı cihaz kullanımı sonucunda nesnelerin interneti, bilgisayar bilimleri dışında, kamu yönetimi alan yazınında da popüler bir konu haline gelmiştir. Nesnelerin interneti kapsamında birbirine internet aracllğıyla bağlanan insanlar, kamu görevlileri, kamu kurumları, kamu hizmeti araçları ve nesneler, kamuda hizmet sunumunun dijitalleşmesi gerekliliğini doğurmuş ve bu yönde gerçekleştirilen uygulamalar gün geçtikçe artmış ve artmaktadır. Bu teknolojinin özel sektörün yanı sıra kamu yönetimine de faydalar sağlayacağının aşikâr olması dolayısıyla, alanda bu konu üzerine yapılan akademik çalışmalar da artmaya başlamıştır. Alan yazını genel olarak değerlendirildiğinde, nesnelerin internetinin; kamu hizmeti sunumunun çeşitli alanlarında etkinlik, etkililik ve verimlilik artısı üzerine odaklandığ1 görülmektedir. Yapılan analizler genel olarak kamu hizmetlerinin belirli alanları üzerine yapılan örneklendirmeler çerçevesinde gelişmiştir. Belirli bir kamu hizmetleri alanlarına (eğitim, sağlık, çevre, güvenlik gibi) yönelik olarak ve o alanı derinlemesine ele alan, alanı nesnelerin interneti çerçevesinde analiz eden çalışmalara, tartışma kapsamının gelişimi açısından büyük ihtiyaç vardır. Söz konusu çalışmalar daha kapsamlı bir şekilde, özellikle bu teknolojinin teknik boyutuna odaklanan bilgisayar bilimcileri ve kamu yönetimi boyutuna odaklanan sosyal bilimciler tarafindan ortak olarak yapılabilecektir.

Bu çalışma, özellikle kamu yönetimi Türkçe alan yazınında eksikliği gözlemlenen, kamu yönetiminde ve kamu hizmetlerinin sunumunda dijital dönüşümün boyutlarından olan nesnelerin interneti boyutuna odaklanmış ve konunun genel hatlarının çizmeyi amaçlamıştır. Dolayısıyla çeşitli kamu hizmetleri alanlarında nesnelerin internetinin yansımalarını, geniş bir Türkçe ve İngilizce alan yazını taraması sonucunda ele almıştır. Çalışmada tespit edildiği üzere, kamu hizmetlerinin sunumunda dijital dönüşüm alan yazınında genel olarak olumlanma eğilimindedir. Konuya karşı özellikle kamu yararı, kamu değeri, kamusal fayda konuları etrafinda geliştirilecek eleştirel bakış açılarına ve çalışmalara ihtiyaç olduğu tespit edilmiştir. Bu yönde yapılacak çalışmalar nesnelerin interneti tabanlı uygulamaların gelişimi açısından da önemli rol oynayacaktır. Son olarak, kamu yönetiminin bu dijital dönüşüm sürecinde bir kullanıc1, düzenleyici ve bunların arasında bir köprü olarak aldığı farklı rolleri ve fonksiyonlanı henüz net olarak belirlenmemiş ve yeterince çalışılmamıştır. Bu konu da ileride yapılacak çalışmaların odak aldığı önemli konulardan birisi olabilecektir.

\section{Kaynakça}

Akın, M. (2006). Elektronik oy verme sistemlerinde güvenlik: deneyimler ve türkiye için öneriler. İstanbul Üniversitesi İktisat Fakültesi Ekonometri ve Istatistik Dergisi, 3, 32-47.

Albatan, Ö. (2014). Kamu servislerinin kentlerde mekânsal sunumu üzerine kuramsal-kavramsal çerçeveler. METU Journal of the Faculty of Architecture, 31(1), 195-214.

Alcatel. (2018). The internet of things for government. France: Alcatel Lucent.

Altınışık, E. (2017). Dijitalleşme söyleminin kamu yönetimi disiplinine olası etkisi: 1950 deneyiminden yola çıkan bir öngörü. Süleyman Demirel Üniversitesi İktisadi ve İdari Bilimler Fakültesi Dergisi, 22, 1933-1943.

ATDE. (2015). Accenture dijitallessme endeksi türkiye sonuçar: türkiye'nin en dijital șirketleri 2015. İstanbul: Türkiye Bilişim Vakfi.

Barth, M. ve Veit, D. J. (2011). How digital divide affects public e-services: The role of migration background. Wirtschaftsinformatik Proceedings, 118, 3-14.

Bertot, J. C., Estevez, E. ve Janowski, T. (2016), Digital public service innovation: Framework proposal. ICEGOV2016. Uruguay, 1-3 Mart.

Bhoomika, K. N., Deepa, C., Rashmi, R. K. ve Srinivasa, R. (2016). Internet of things for environmental monitoring. International Journal of Advanced Networking \& Applications, 497-501.

Brous, P. ve Janssen, M. (2015). Advancing e-government using the internet of things: A systematic review of benefits. 14th International Conference on Electronic Government (EGOV). Greece, 30 Ağustos-3 Eylül.

Castro, D., New, J. ve McQuinn, A. (2016). How is the federal government using the internet of things? Washington: Center for Data Innovation.

Chunquan, D. ve Shunbing, Z. (2012). Research on urban public safety emergency management early warning system based on technologies for the internet of things. Procedia Engineering, 45, 748 - 754.

Çal, S. (2009). Kamu hizmeti kavramı üzerine kimi düşünceler. http://www.idare.gen.tr/cal-kh-dusunceler.pdf., E.T.: 14.02.2019.

Çapar, S., Demir, R. ve Yıldırım, Ş. (2015). Kamu hizmet sunumunda idarecilerin işlevi. Türk İdare Dergisi, 481, 361 399.

Davidsson, P., Hajinasab, B., Holmgren, J., Jevinger, A. ve Persson, J. A. (2016). The fourth wave of digitalization and public transport: opportunities and challenges. Sustainability, 8, 1-16. 
Demir, L. (2013). Kamu hizmetleri. http://www.muharrembalci.com/hukukdunyasi/makaleler/birikimlerI/67.pdf, E.T.: 12.01.2019.

Eggers, W. D. ve Macmillan, P. (2015). Deloitte, kamu 2020: Kamunun geleceğine yolculuk. İstanbul: Deloitte.

El-Haddadeh, R., Osmani, M., Thakker, D., Weerakkody, V. ve Kapoor, K. K. (2018). Examining citizens' perceived value of internet of things technologies in facilitating public sector services engagement. Government Information Quarterly, 36, 310-320.

EP. (2016). Potential and challenges of e-voting in the european union. EU: European Parliament.

Erkul, R. E. (2009). Sosyal medya araçlarının (Web 2.0) kamu hizmetleri ve uygulamalarında kullanılabilirliği. Türkiye Bilişim Derneği, 116, 96-101.

Eryılmaz, B. (2015). Kamu yönetimi (11. Bask1). Kocaeli: Umuttepe Yayınları.

Fraga-Lamas, P., Fernández-Caramés, T. M., Suárez-Albela, M., Castedo, L. ve González-López, M. (2016), A Review on internet of things for defense and public safety. Sensors, 16, 1-44.

GOS. (2014). The internet of things: Making the most of the second digital revolution. UK: UK Government Chief Scientific Adviser.

Govloop. (2016). Your questions answered: the internet of things in government. USA: Govloop.

Göçoğlu, V. (2014). Kamu politikası ve sosyal medya ilişkisi (Yüksek Lisans Tezi). Hacettepe Üniversitesi, Sosyal Bilimler Enstitüsü, Ankara.

Göker, Z. (2016). Gelir dağılımının iyileştirilmesinde kamu hizmetlerinin rolü. Calışma ve Toplum, 4, 1731-1746.

Gözler, K. (2003). İdare bukuku. Bursa: Ekin Kitabevi.

Gunashekar, S., Spisak, A., Dean, K., Ryan, N., Lepetit, L. ve Cornish, P. (2016). Accelerating the internet of things in the UK: using policy to support practice. California and UK: RAND Corporation.

Gül, H. (2018). Dijitalleşmenin kamu yönetimi ve politikaları ile bu alanlardaki araştırmalara etkileri. Yasama Dergisi, 36, 5-26.

Huawei. (2018). IoT security white paper. China: Huawei.

İnce, N. M. (2001). Elektronik devlet: Kamu biz̧metlerinin sunulmasında yeni imkânlar. Ankara: Devlet Planlama Teşkilatı.

Kantarci, B. ve Mouftah, H. T. (2014). Trustworthy sensing for public safety in cloud-centric internet of things. IEEE Internet Of Things Journal, 1(4), 360-368.

Karatoprak, E. (2010). Kamu hizmetlerinin sunumunda benimsenen yeni yöntemler ve uygulamaların kontrolü. Maliye Dergisi, 159, 365-375.

Kaya, A. ve Mursül, D. (2017). Dijital Türkiye projesi kapsamında kamu hizmetlerinin dönüşümü. Yü̊üncü Yal Üniversitesi Sosyal Bilimler Enstitüsü Dergisi, 1(4), 1-11.

Lindgren, I. ve Veenstra, A. F. (2018). Digital government transformation: a case illustrating public e-service development as part of public sector transformation. 19th Annual International Conference on Digital Government Research. Delft, 30 May-1 June.

Maissin, J. P., Elst, R. V. ve Colin, F. (2015). How will IoT improve public sector services? UK: Deloitte.

Mecek, M. (2017). E-devlet ve e-belediye: Kavramsal çerçeve ve türkiye'de belediye web sitelerine yönelik yapılan çalışmaların incelenmesi. Süleyman Demirel Üniversitesi İktisadi ve İdari Bilimler Fakültesi Dergisi, 22, 1815-1851.

Mergel, I., Kattel, R., Lember, V. ve McBride, K. (2018). Citizen-oriented digital transformation in the public sector. 19th Annual International Conference on Digital Government Research : Governance in the Data Age. Delft, 30 May-1 June.

Negiz, N. ve Saraçbaşı, Y. (2012). Demokratik yönetişim sağlanmasında e-belediye ve uygulamaları: Akdeniz bölgesi örneği. Bilgi Ekonomisi ve Yönetimi Dergisi, 7(1), 42-52.

Odyakmaz, Z., Kaymak, Ü., ve Ercan, İ. (2009). İdari yargı, konu soru mevそuat. İstanbul: Oniki Levha Yayıncilik.

Onar, S. S. (1992). İdare bukukunun umumi esaslar. İstanbul: Marifet Basimevi.

Ömürgönülşen, U. (2003). Kamu sektörünün yönetimi sorununa yeni bir yaklaşım: Yeni kamu işletmeciliği. İçinde M. Acar ve H. Özgür(Der.) Cağdaş Kamu Yönetimi I (ss. 3-43). Ankara: Nobel.

Özer, M. A. ve Otyzbay, Z. (2018). Türkiye ve Kazakistan örneğinde e-devlet uygulamalarının kamu yönetiminde verimliliğe etkisi. Verimlilik Dergisi, (4), 71-91.

Patel, K. K. ve Patel, S. M. (2016). Internet of things-IOT: Definition, characteristics, architecture, enabling technologies, application \& future challenges. International Journal of Engineering Science and Computing, 6(5), 61226131.

Plantinga, M., Ridder, K. ve Corra, A. (2011). Contracting out public services - the need and necessity of government intervention for safeguarding public interests (Çev: O. Doğan). KMÜ Sosyal ve Ekonomik. Araştırmalar Dergisi, 13(21), 103-117.

Ramamurthy, A. ve Jain, P. (2017). The internet of things in the power sector opportunities in Asia and The Pacific, ABD. Sustainable Development Working Paper Series, 48, 1-36.

Roy, J. (2017). Digital Government and service delivery: An examination of performance and prospects. Canadian Public Administration, 60(4), 538-561.

Schou, J. ve Hjelhot, M. (2018). Digitalization and public sector transformations (1. Edition). Palgrave Macmillan.

Sezer, Ö. (2008). Kamu hizmetlerinde müşteri (Vatandaş) odaklılık: Türkiye’de kamu hizmeti anlayışı açısından bir değerlendirme. ZKÜ Sosyal Bilimler Dergisi, 4(8), 147-171.

Sezer, Ö. ve Vural, T. (2010). Kamu hizmetlerinin sunumunda devletin değişen rolü ve merkezi yönetim ile yerel yönetimler arasında yetki ve görev paylaşımı. Maliye Dergisi, 159, 203-219. 
Şen, N. G. ve Acar, Ü. (2017). Kamu hizmetlerinin sunumunda alternatif yöntem ve modeller: Türkiye'den uygulama örnekleri. Maliye Araştırmalar Dergisi, 3(2), 147-172.

Takagi, H. ve Mima, T. (2016). Use of IoT by government institutions. Hitachi Review, 65(1), 735-740.

TDK. (2019). Kamu, http://www.tdk.gov.tr/index.php?option=com_bts\&arama=kelime\&guid=TDK.GTS.5c626a46aa03c4.414388 60, E.T.: 12.01.2019.

Tunç, A., Belli, A. ve Aydoğdu, Y. (2017). Dijitalleşen kamu hizmetleri açısından gida tarım ve hayvancılık bakanlığ1 değerlendirilmesi. Süleyman Demirel Üniversitesi İktisadi ve İdari Bilimler Fakültesi Dergisi, 22, 1921-1931.

Usta, S. ve Bilgiç, E. (2016). Yerel yönetimlerde hizmet sunumu: kamu özel ortakllğ1 modeli. Süleyman Demirel Üniversitesi Sosyal Bilimler Enstitüsü Dergisi, 1(23), 249-267.

Ünal, F. ve Kiraz, İ. (2016). Türkiye'de e-devlet uygulamalarının kamu hizmetlerinin sunumunda etkinliği: Adalet bakanlığı UYAP bilişim sistemi örneği. Dumlupinar Üniversitesi Sosyal Bilimler Dergisi, Afro-Avrasya Özel Sayısı, 437450.

Vermesan, O. ve Friess, P. (2014). Internet of things-from research and innovation to market deployment. Denmark: River Publishers.

WhitePaper. (2017). The citizen view of government digital transformation 2017 findings. UK: Sopra Steria.

Xiangxuan, X. (2017). The contextual dynamics of internet of things applications in smart public bike sharing services. Chinese Journal of Urban and Environmental Studies, 5(2), 1-20.

Yalçın, R. Ü. (2011). Türk kamu yönetimi reform sürecinde kamu biz̨met sunumu: Değıșim ve etkinlik bağlamında kamu bižmet standartlar ve uygulamalar (Yüksek Lisans Tezi). Selçuk Üniversitesi, Sosyal Bilimler Enstitüsü, Konya.

Yıldız, M. (2006). Kamu siyasaları açısından cep telefonu teknolojisi ve mobil devlet. Hacettepe Üniversitesi İIBF Dergisi, 24(1), 241-263.

Yıldız, M. (2011). Kamu politikası. Türkiye Bilimler Akademisi Açle Ders Malz̨emeleri, http:/ / www.acikders.org.tr/course/view.php?id=66, E.T.: 10.01.2019.

Zheng, L., Zhang, H., Han, W., Zhou, X., He, J., Zhang, Z., Gu, Y. ve Wang, J. (2011). Technologies, applications, and governance in the internet of things. Internet of Things. Global Technological and Societal Trends.

\section{EXTENDED ABSTRACT}

Public services delivery implementations differ from country to country depending on the factors such as the culture, ideology, regime, and economic and politic agenda. As a reflection of these factors, the idea sprawled in the early 20th century, indicated that states should be more effective in social services and public services should be diversified with the understanding of the social welfare. In addition, the liberalization policies and the contraction of the state, which became influential after 1980s, supported the option of delivering public services by the private sector rather than by the central and local government organizations. There are also some external factors affecting these implementations. The process of globalization that made the boundaries of countries ambiguous and the information age that changes the way of production and share of information are the examples of these factors.

Individuals, institutions, business areas and even objects are moving rapidly in the direction of digitalization. With this digital transformation, radical changes have taken place in almost every area of daily life. For example, individuals' living, consuming and working patterns, habits and value judgments have begun to change. Particularly, in recent years, with these developments in information and communication technologies, the widespread use of the internet, the transition to the information age and the Industry 4.0 period, the way of public services delivery has transformed. In the field of public administration, e-government applications are presented as the most concrete form of digital transformation in public service delivery. E-government applications have emerged as information sharing tools of public services on public institutions regarding web sites and various digital platforms on the basis of open access. With this application, which is called Open Government Data, the information about residents can be accessed by public institutions and be used in order to provide public services. Egovernment has appeared as a project where the state provides public services faster, more effective and efficient on the other hand, the citizen obligations towards the state and public transactions have been established more easily and quickly, seamlessly and safely.

People, machines, vehicles, equipment; shortly the things, which have become connected to each other via internet, have moved the issue that is called as internet of things, to the public administration agenda. Describing in a larger statement, things that are interconnected in this world are not just computers, but machines, vehicles, smartphones, home accessories, wearable technologies, toys, cameras, healthcare equipment, animals, people, buildings and even cities. This is a world where millions of people and objects are connected to each other through the internet network, where information is regularly produced, analyzed and shared for various purposes. As a conclusion of the Internet of things, central and 
local governments have begun to use sensors, advanced networks, wearable technologies and GPS systems to deliver public services more effectively, effectively and efficiently. Local governments will be able to provide a safe urban life service to citizens by monitoring the public transport, roads and continuously monitoring the information flow and urban operation in the cities with sensors and monitoring systems. Together with smart cities, energy management can be realized with a better supplydemand analysis for saving. With improved and proactive monitoring systems, service offerings can be delivered faster and in a cost-effective way. Finally, these systems will allow for more immediate response to emergencies and crisis in cities. These practices are concrete examples of the digital transformation in the delivery of public services.

This study analyzes the digital transformation experienced in public service provision in the information society on the basis of public administration discipline, in the context of the internet of things, by reviewing of related literature and reports. The research question of the study was determined as "What are the dimensions of digital transformation in public services delivery and what is the function of IoT in new public services delivery approach?". To find the answer of this research question, a comprehensive literature view conducted on Turkish and English scientific studies. Addition to these, related company reports are examined in order to enlarge the findings. The applications covered by the Internet of things are handled within the scope of various public services and examples for applications are given. Systematically, in the first part of the study, the conceptual framework of public services and public services delivery is presented. Second part of the study includes the subject of digital transformation in public services delivery. Third part of the study discusses the use of IoT in public services delivery in recent years. Finally, in the conclusion of the study, some suggestions for future studies on the subject are presented. 